\title{
Using Persona Descriptions to Inform Library Space Design
}

Holt Zaugg

Brigham Young University, holt_zaugg@byu.edu

Follow this and additional works at: https://scholarsarchive.byu.edu/facpub

Part of the Library and Information Science Commons

\section{Original Publication Citation}

Holt Zaugg (2017), Using Persona Descriptions to Inform Library Space Design, in Samantha Schmehl Hines, Kathryn Moore Crowe (ed.) The Future of Library Space (Advances in Library Administration and Organization, Volume 36) Bingley, UK - Emerald Group Publishing Limited, 335-358.

\section{BYU ScholarsArchive Citation}

Zaugg, Holt, "Using Persona Descriptions to Inform Library Space Design" (2017). Faculty Publications. 1807.

https://scholarsarchive.byu.edu/facpub/1807

This Book Chapter is brought to you for free and open access by BYU ScholarsArchive. It has been accepted for inclusion in Faculty Publications by an authorized administrator of BYU ScholarsArchive. For more information, please contact ellen_amatangelo@byu.edu. 
Using Persona Descriptions to Inform Library Space Design

The final chapter in "The Future of Library Space"

\section{Holt Zaugg}

Brigham Young University 


\begin{abstract}
Purpose: Library space and services should center on library patrons and what they need. Trying to match the needs of each patron can become a daunting task. A new approach needs to be taken. One that describes patrons and their needs in a useful way. Using an approach from marketing and product design, personas or user groups, offer a unique approach to thinking and describing patron needs to assist in the identification and design of library space and services.

Design \& Methodology: The identification, development, and validation of personas employs an iterative process using both qualitative and quantitative methods to first identify user patterns, then develop the patterns into meaningful descriptions, and finally to validate the personas. Once validated, additional data is collected, and, as librarians become persona-minded, the persona descriptions continue to be enriched.

Findings: The chapter provides a descriptions of personas found in one academic library and how those personas were developed before being used to assist in library space identification and development. One unique feature of our personas was the fluid nature where patrons would shift personas depending on personal needs.

Practical implications: Personas are a practical and meaningful tool for thinking about library space and service design in the development stage. Several examples of library spaces that focus on the needs of specific personas are provided.

Keywords: personas, user groups, library design, library space, patron needs
\end{abstract}




\section{What are Personas?}

\section{Introduction}

Imagine a room containing a thousand people. You are tasked with understanding and meeting each individual's needs. Quite a daunting task! Now imagine the same room but with only five people and the same task of understanding and meeting each individual's needs. This is doable. This is the world of personas.

Primarily used in the world of marketing and design, personas or user groups refers to groups of individuals who have common use patterns and needs (Guenther, 2006; Mckay, 2010; Mulder and Yaar, 2007; Olsen, 2004; Pruitt \& Grandin, 2003; Schmidt, 2014). The persona is a description of a single person who represents a subgroup of users with common needs. In marketing and design the persona is often fleshed out with a picture, a name, and other background information (age, residence, etc.) to make the persona sound like a real person. When reading the persona description, one often comments that he or she knows someone just like that. In this way the persona becomes the model designers use when planning for new products or activities.

Personas help librarians understand and track the needs of patrons such as improving library Chat services (Al-Shboul and Abrizah, 2014; Tempelman-Kluit and Pearce, 2014). This chapter describes the process by which personas may be identified, developed, and validated. It provides examples of personas found at a large, private, mid-western university library and how personas can be used in designing library spaces.

\section{Identification}

Identifying the personas within your library requires you to assume the role of a patron and look for what patrons are doing and why they are they do the things they do especially those unlike you. Initial identification uses a variety of sources. First, a review of case studies of different library assessment projects and activities provides tidbits of how library patrons think and act. For example, Branin (2007), in explaining renovation plans, describes the old library space that was initially used to read and study, but changed because of the increasing need for book storage. The renovation plans focused on what patrons wanted in the future physical space - a place to study and interact. In seeking input from faculty and students, the design plans envisioned what a $21^{\text {st }}$ Century library could look like.

Others have identified specific user needs that are flexible for a wide variety of activities. This includes space to collaborate, to work, to play, and to use technology (Brown, 1992, Cha and Kim, 2015; Cohen, 2009). Each of these studies examine how the library is used from the eyes of the user. Library designers suspended their own experience and replaced it with what the patron wanted (Fortini-Campbell, 2001; Olsen, 2004; Pruitt and Grudin, 2003).

A second step is to examine library collected data on patron activities, including such things as computer and printer use logs, surveys of library patrons' perceptions, observation of patrons' activities, and use of group study rooms. Each data set informs the persona designer on how patrons currently use libraries. Persona designers look for reoccurring use patterns, both obvious, such as students studying, and subtler, such as the 
students who game on a large screen TVs in the media center. The data review enables one to develop persona theories of how the patrons use and interact with the library.

\section{Development}

Once the initial persona theories are identified, a variety of data collection methods are used to further develop those personas. Typically interviews, focus groups, and observations are used to gain further understanding on the identified personas (Cunningham, 2005; Muldaer and Yaar, 2007). For example, in interviews, one may be asked to tell of a time when he or she needed something. This interview identifies how the person used the library. It either validates the current persona descriptions or facilitates any changes to the persona theories.

Because people do not always remember all of the details or selectively leave out key parts of their experience, observations are more important than the recounting of events. Observations provide a persona developer specific examples of the patron's actions and provides direct evidence of the persona theories. Ethnographies require the persona developer to follow patrons as they use the library and ask what patrons are doing and why they are doing it. Recording these activities enables multiple reviews to gain greater insights into what the patron does and why. It helps to connect the patron's actions to their needs and wants (Goodman, 2011; Khoo, Rozaklis, \& Hall, 2012).

Sometimes the developer may engage patrons in usability studies. Patrons are asked to perform specific tasks typical of patrons needs. Following patrons as they complete the usability task provides better understanding of the patron needs. Care needs to be taken in what tasks are requested and how comfortable the patron is in performing the task. Usability studies also provide insights from a wide range (novices to experts) of patrons.

As this data is collected and reviewed, the initial personas are refined. In some cases, the personas are validated with additional supporting information. In other cases, persona descriptions are too broad and the persona is split into differentiated personas with some common elements. The split is akin to describing identical twins. While very similar, there are key differences between the twins. Some personas appear similar but have key needs that differentiate them from similar looking personas.

Finally, additional data may indicate that two personas, initially thought to be distinct, are really one and the same persona. In this case the additional data provides evidence why the two personas should be combined. Throughout this process, the persona designers use a cyclical process to examine data, to discuss patterns, and to modify descriptions so the persona descriptions fit the data.

One method has persona developers split into groups who independently identify and develop their own personas. Each group presents evidence justifying their personas to one another. This process both enriches the persona descriptions and serves as an initial validation. Identifying and describing the same use pattern as an independent group is an indication of a correct description. A similar presentation process may also occur with librarians, who may indicate areas where data should be re-examined to further flesh out personas. With the final descriptions of personas complete, developers are ready to validate the personas. 


\section{Validation}

Persona validation is typically done using quantitative methods. Several statements describing the behavior and preferences of each persona are written. There is no set rule regarding how many statements are needed, but there needs to be a balance between enough and too many statements. This study used the minimum of one statement per persona because 10 library patron personas were developed. Other efforts, with fewer personas, may use more. Using the statements patrons are asked to indicate which statements reflect their personal use patterns. This process validates the personas as correct descriptions of needs and the degree to which the persona represents the use pattern among all patrons (Zaugg, et al., in press).

A secondary validation may also be conducted using a principle component analysis (PCA) to determine if personas correlate with each other into more compact definitions (Blomquist and Arvola, 2002; Hellsrom and Ericksson, 2013; Leary and Allen, 2011). This additional validation groups personas into neighborhoods where distinct personas have mutual needs and similar use patterns. It condenses the persona descriptions to help librarians to link the use patterns of one persona to the use patterns of another.

\section{Persona Development Methods}

In the 2013-2014 school year the Harold B. Lee Library at Brigham Young University identified, developed, and validated personas for their undergraduate student patrons. The personas focused on patrons who come to the library to use the facilities and access Lee Library services. As just described, the identification and development of undergraduate personas in the Lee Library required several data collection steps and analysis iterations. As the identification and development process were labor intensive, students, as part of a Communications 432 course project, were used as student researchers. They were divided into three groups of four to six students with the intent that each group would independently identify and develop their own personas.

Initially, the student researchers examined 12 de-identified, library assessment studies to create their initial persona theories. Once persona theories were in place, each student research group devised a strategy for collecting more data to verify and expand upon the identified personas. The additional data collection strategies included focus groups, interviews, observations, and ethnographies. The use of each data collection strategy varied in the degree of use depending upon each specific research group. Each data collection strategy is briefly described below.

\section{Focus groups}

Groups of 8 to 12 student participants were asked a series of questions as a group, but each student was also invited to respond individually to each question. Focus groups typically took 45-60 minutes. Lunch was provided and the session was video recorded for accuracy and to assist analysis.

\section{Interviews}

There were two types of interviews, patron and expert. Patron interviews involved undergraduate students in the Lee Library who were using its services. Students were This article is (c Emerald Group Publishing and permission has been granted for this version to appear here (https://sites.lib.byu.edu/scholarsarchive/). Emerald does not grant permission for this article to be further copied/distributed or hosted elsewhere without the express permission from Emerald Group Publishing Limited. 
asked to identify their use patterns in and experiences with the Lee Library. Expert interviews involved library faculty and staff, who were asked to provide descriptions of how undergraduate students used the Lee Library. Each interview took 10 to 20 minutes and was audio recorded.

\section{Observations}

Observations occurred within the library at randomized locations. Student researchers sat in the designated location and observed student use and interaction patterns for that area. Observations were typically for a 2-hour period at a various times and locations.

\section{Ethnographies}

When using ethnographies, research students, with permission, follow a patron as he or she used the library. The student researcher typically followed from a distance of 10-20 feet so as not to intrude on the patron's activity. However, if the patron was doing something the observer did not understand or needed more explanation about, the observer would briefly interact with the patron to determine what the patron was doing and why.

Following this data collection and analysis, each student research group revised their persona descriptions and presented these descriptions to the other two groups as a class assignment. The Assessment Librarian sat in on these class presentations and asked pertinent questions to help students focus on elements they may not have considered in their analysis. Following these presentations students had time to make final revisions on their personas, prior to presenting them to the library administration.

After the presentations to library administration, similar personas from each research group were combined forming a set of 10 library personas. In this final set, each persona had a unique name, a symbol representing the persona, a brief description, and a quote from focus group or interview data to help clarify the persona description. No other background information was provided as it would differentiate personas as either male or female when the persona could be either gender and the additional description information tended to be quite similar as all personas were fairly homogeneous undergraduate students.

Personas were validated using an in-person and online survey. Both surveys had identical content and only differed in the administration method. One was administered in person in neutral (non-library) areas on campus. The other method sent an online version of the survey to a random sample of undergraduate students.

The survey was a brief, five-question survey focusing on student demographic data (i.e. gender, year of study, college, etc.) and one question asking students to read 10 brief library use descriptions (based on a specific persona) and choose the use description that most closely described their primary use of the library.

Using this data, a principal component analysis (PCA) was conducted. This analysis helped to group personas into common neighborhoods. It also identified if any persona functioned independently from the other personas. The PCA also helped to identify 
overlaps between specific personas. This process provided a more multifaceted description of patrons and identified interrelationships between personas.

\section{Harold B. Lee Library Patron Personas}

The initial persona identification and description process provides a unique view into the use and need patterns of BYU undergraduate students. Each identified persona is briefly described below and key quotes provided by students to indicate the use patterns that helped to define each persona. While personas are typically given a name and picture, we opted to provide a name related to the use pattern, persona symbols, and a description that focuses solely on the use patterns of each persona.

\section{Explorer}

This persona includes patrons who come to the library to discover what the Lee Library has to offer. The explorer will look around for new things to discover and new opportunities to learn and use what the library has to offer. The exploring may or may not be directly linked to course assignments, but comes from a desire to learn new things and discover new opportunities.

Patrons in this group are characterized by the quotes:

I just like libraries in general. I like being able to find random things, for example the 4th

floor music history library is cool, and the place where they have vinyl records, I'd go there to relax and listen to the vinyl records.

The library has nice stuff and a lot of resources. They've got the best types of cameras and stuff to check out (Zaugg et al., 2015).

\section{Collaborator}

This persona has two subgroups - compelled and voluntary collaborators. The compelled collaborators are students taking the same course who are placed in a group to work on a specific class project or learning task. Typically students do not initially know each other, but instances may occur where some of the group members know each other. These groups typically have 5-8 members but size is dependent on the class and the specific assignment. The voluntary collaborators are friends who are taking the same course. Although they are not required to work together on a learning task, they will join together to help one another. Two or more students make up this kind of collaboration.

Regardless of subgroup, collaborators are motivated to get good grades. Collaboration is seen as a means to this end. They are typically found in library areas that allow for discussion such as No Shhh Zones or group study rooms. They openly share their talents and abilities while discussing ideas, sharing thoughts, and assisting each other in completing assignments. A comment typical of this persona is:

I do use group rooms a lot. I have had a lot of group projects, or just study groups, so we'll reserve a group study room (Zaugg et al., 2015).

\section{Focuser}

The most common and most expected persona is the Focuser. This group includes highly motivated individuals who prefer to study alone and in quiet. They avoid anything (https://sites.lib.byu.edu/scholarsarchive/). Emerald does not grant permission for this article to be further copied/distributed or hosted elsewhere without the express permission from Emerald Group Publishing Limited. 
that will provide a distraction or interruption. They often seek library spaces that are designated as quiet study areas and will even go as far as to find areas that have poor cell phone reception so no incoming calls, texts, or social media updates will disturb them. They will occupy tables, individual study carrels and, if available, will use a group study room alone. They equate the library with a place to study and focus their learning efforts. Their focus is on completing the tasks on time and getting a high grade. A comment indicative of Focusers is:

When I'm in the library I feel like I'm more effective, even if that's not true. My mind knows I'm here to study whereas if I'm at my house I don't study. My mind associates studying with the library (Zaugg et al., 2015).

\section{Side-Kicks}

This persona overlaps with the Focuser and Collaborator personas, but has significant differences. They are dedicated students who seek to get top grades on all assignments, but they draw energy and motivation from being in a group. They will typically study different subject material from other group members, but the subject material is not the focus. They want to be around others because it helps them to focus on their own studies. They are typically found at tables in groups of two to four students, but the group size may be larger. They may also study independently, but in an area that has other students who are also studying. They are social enough to need someone nearby, but focused enough to work on their assignment. One will often find a mix of students ranging from freshmen to seniors in this group. In these cases the seniors often mentor the freshmen on how to use the library effectively. Comments typical of Side-Kicks are:

Usually the same amount of work gets done when I'm with a roommate, they just help me not be so lonely.

When I see other students studying, it gives me the feeling that they are being responsible and working hard so I should too (Zaugg et al., 2015).

\section{Islander}

This persona is summarized by the phrase, Location, Location, Location! Most of these students are quite similar to those in the Focuser persona, but they are also found in other persona groups. They are differentiated from other personas by having a designated spot where they like to be. This may be a preferred table, an individual study carrel, a group study room, a specific reading chair, or simply a spot where they feel comfortable. The spot often suits their personality and study habits while meeting their specific needs. During peak library use times, Islanders are not always able to use their preferred spot and this can be somewhat distressing for them. They will also take measures to extend the use of a specific area by partnering with others or engaging in practices that extend reservation time. Their activities in this space may or may not be school related, but it is "their" space. Typical comments are:

I love that there's classical music playing because it helps me study and relax. I feel like it is my main area of the library.

You can find your own spot where no one can bother you (Zaugg et al., 2015). 


\section{Socializer}

Studying and learning are not the primary focus of this persona. They see the library space as a social gathering place to meet old and new friends. They come to the library to visit over breaks between class, to relax from the stress of schoolwork, or simply to socialize with others. They are typically talkative and loud. They usually congregate in areas that allow eating and noise. The primary purpose of their library visit is to socialize, including flirting. A typical comment is:

I've tried to get dates on the 4th floor before. I've had about a 50/50 success rate. I've gone to flirt before (Zaugg et al., 2015).

\section{Chillaxer}

Patrons in this persona group blend work and pleasure in their use of the library. They are equally comfortable studying, gaming, or streaming a video. They enjoy the combination of library services and the atmosphere in the library. They have no qualms about taking a break from studying to do something else, including taking a nap. They seem to have a strong balance between work and relaxation. They see the library as a place that facilitates both activities. A typical comment was:

I like to come to the library instead of the CADM lab to do my engineering assignments because the Internet is faster. When I get tired, I take breaks to watch YouTube (Zaugg et al., 2015).

\section{In-n-Outer}

As the name implies, the patrons in this group come into the library for a specific, typically, singular purpose. They will complete the task and promptly leave. The purposes and tasks vary and may include a consultation with a librarian, printing a paper that is due for an upcoming class, checking email or social media during a short break, or picking up resource material that is on hold for them. They see the library as a place to access services, but they do not want to spend any more time in the library than is necessary. Typical visits are usually less than 15 minutes long with librarian consultations being the exception. Because of the brief nature of these visits, no patron was able or willing to be interviewed so no quotes typical of the group were collected (Zaugg et al., 2015).

\section{Pirate.}

For students in this persona group, the library is seen as a place of convenience. It has up-to-date technology and applications that allow the patron to come in and use the resources so they do not have to provide them. Students will typically bring a flash drive to plug into one of the public computers in the library so they do not need to bring their own computer with them. They are just as likely to use an up-to-date application found on a library computer or library equipment, like the sound room, for school or personal use. These patrons are typically found in the library's public computer labs or in the media center. A quote typical of this persona is:

Why would I buy my own laptop if I can use a computer here (Zaugg et al., 2015)?

This article is (C) Emerald Group Publishing and permission has been granted for this version to appear here (https://sites.lib.byu.edu/scholarsarchive/). Emerald does not grant permission for this article to be further copied/distributed or hosted elsewhere without the express permission from Emerald Group Publishing Limited. 


\section{Outsider}

This persona was a known group, but not examined during the study. This persona represents patrons who visit and use library resources online or who do not enter the library for a specific reason. Since the study focused on patrons in the library, this persona was not directly observed nor was a description provided beyond that of people who use library resources online or who have reservations about entering the library. Those accessing services online are typically akin to focusers who want to get things done in a quick and efficient manner, but who, for a variety of reasons, have another place where they prefer to study. From a few focus group and interview comments, we also believe that this persona includes subgroups of students new to BYU, who are overwhelmed by the size and complexity of the library, or those students in a major does not require much use of the library, but no validating data has yet been collected to verify these suggestions. Efforts are currently underway to help further identify this persona and any subgroups that may exist in it. A comment typical of this group is:

I feel like it is so quiet. I don't need to use the books, and everything I need is on my computer. I can't eat in there, I can't mess anything up. I don't go to the library (Zaugg et al., 2015).

There is one final note regarding individual personas. Personas in other fields are considered to be somewhat stable. That is, a patron who fits into a specific persona will remain in that persona. However, as data was collected, there was sufficient evidence that indicated patrons use a variety of personas depending on the time of year and their specific needs. For example, one patron's principle persona may be the Socializer persona, but when a mid-term exam or paper looms, he or she will switch to another persona (i.e. Focuser, Islander, Collaborator) to meet his/her needs. Similarly, someone who is a Focuser may become an Explorer when a study assignment reveals a service or resource the library has that meets another need. Essentially, students have loyalty to a persona as long as the persona meets their needs. Switching personas indicates user flexibility in what they need and how they use the library. This supports findings from Idoughi, Seffah and Kolski (2012) that determined users have a principle persona that defines the user's primary activity. The primary persona is used for a host of evaluation and planning activities, but other, less dominant personas also have an impact on planning and service design.

\section{Principle Component Analysis Groups}

The Lee Library also conducted a principle component analysis (PCA) to determine how these 10 personas may relate with each other. A PCA is a statistical procedure that uses responses from students on statements representing each persona to determine if the developed persona is correct and how strongly personas correlate with one another. Others have used similar methods to further collapse persona descriptions (Blomquist and Arvola, 2002; Hellstrom and Erikson, 2013; Leary and Allen, 2011). Where possible personas are formed into clusters that indicate a common construct that is often difficult to measure but indicates that two or more personas correlate with each other in some way. In this effort, four such clusters were found and labeled. In this study clusters are referred to as persona neighborhoods because each cluster has different personas but all personas

This article is @ Emerald Group Publishing and permission has been granted for this version to appear here (https://sites.lib.byu.edu/scholarsarchive/). Emerald does not grant permission for this article to be further copied/distributed or hosted elsewhere without the express permission from Emerald Group Publishing Limited. 
have common uses or needs. They include social-oriented, task-oriented, collaborationoriented, and tool-oriented neighborhoods. A percent score is provided that indicates what percent of the total patron population is represented by the primary personas in each neighborhood. Each neighborhood is described below.

\section{Social-oriented}

This neighborhood of personas is characterized by activities that are not typically focused on an academic goal, but may have an academic component. Interactions with others or with new material, not academic pursuits, are the primary focus of this group. Personas found in this neighborhood include the Explorer, Socializer, and Chillaxer. This neighborhood accounts for approximately 7\% of all patrons (Zaugg et al., 2015).

\section{Task-oriented}

Personas in this neighborhood exhibited an interesting trend unique to this cluster. While two of the personas correlated in a positive way, the third correlated with equal strength, but in an opposite direction. The common construct in this persona was the intent to complete course work, projects, or research in the most efficient and effective manner possible. It includes the Focusers, Islanders, and Outsiders. The Focuser and Islander are positively correlated to each other but negatively correlated to the Outsider. This relationship is explained by the location of activities patrons in these groups engage in. While each persona uses library resources in an effective and efficient manner, the Focuser and Islander do so within the library while the Outsider does not. Approximately $49 \%$ of all library patrons are found in this neighborhood (Zaugg et al., 2015).

\section{Collaboration-oriented}

This neighborhood includes the Collaborator and Side-Kick personas as they have the common thread of wanting to work with others. While they are focused on getting good grades and completing work on time, they primarily draw their energy from collaborating with others. The social interaction of learning is what motivates and drives them to do better both in learning from others and providing help to others. They need to have contact with others while studying or researching. This neighborhood accounts for $21 \%$ of patrons (Zaugg et al., 2015).

\section{Tool-oriented}

The Pirates and In-n-Outer personas, found in this neighborhood, view the library as a workshop or resource center. They come to use specific tools needed to complete a personal or educational task, but do not linger in the library. While most library visits are short, these patrons see the library as a place where specific tools and resources are stored and where these resources may be accessed and used to help them with whatever task they are trying to complete. Approximately $23 \%$ of all patrons have these personas as their primary persona (Zaugg et al., 2015). Figure 1 summarizes the percent of total for each persona and the neighborhoods into which the personas are grouped.

As a final note, validation procedures for this effort asked patrons to identify their dominant person (which single statement was most like the way they used the library). 
However, a validation effort that allowed students to identify all personas they used while in the library may offer a more complete picture of how personas are interconnected and result in some changes in the neighborhood descriptions (PCA analysis). However, it is believed that the dominant personas provide sufficient information to indicate persona neighborhoods and to use for identification and development of library spaces used by the personas either individually or as a neighborhood.

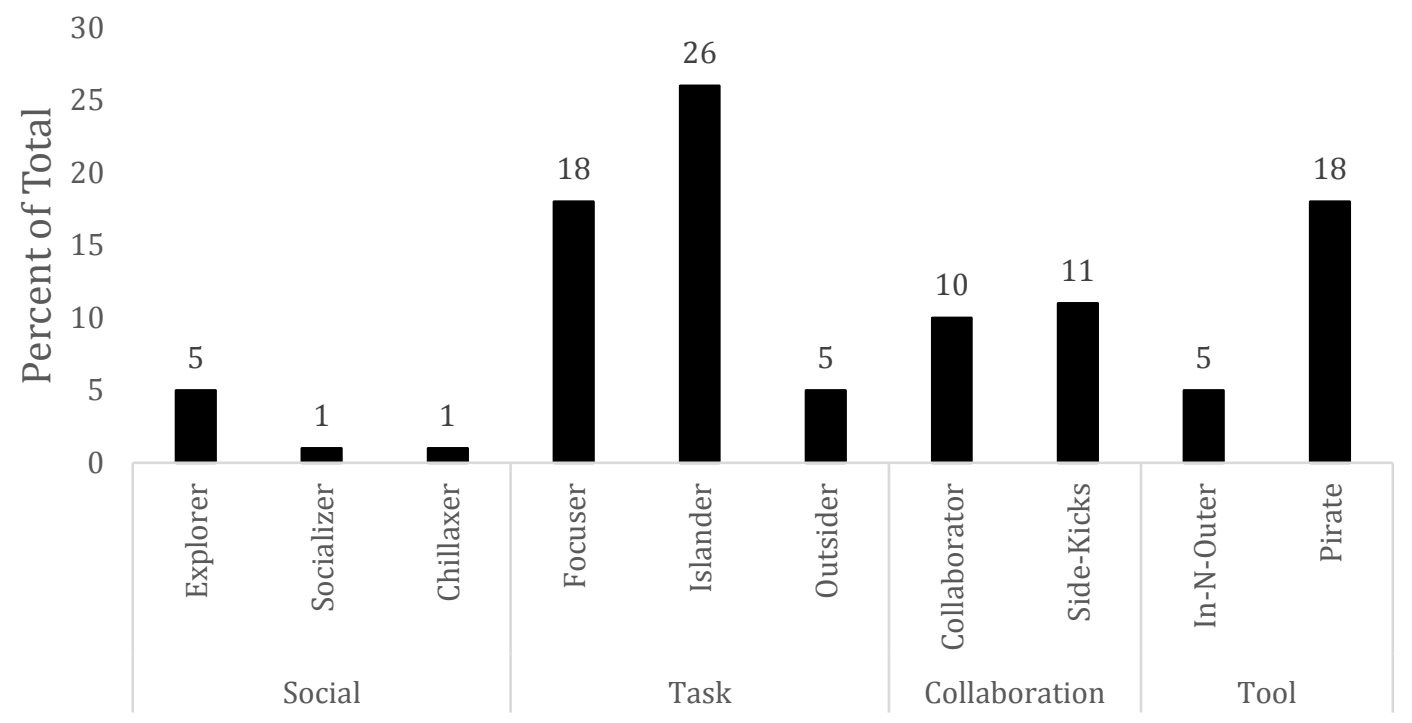

\section{Personas}

Figure 1. Percent of total summary for each persona by neighborhood.

\section{Using Personas to Develop Library Space}

In using personas, librarians need to understand how personas work and how they can use personas to identify and develop library spaces. This process involves seeing patrons differently, based on their behavior and needs. It also uses the neighborhoods associated with personas to look for additional connections. For example, if a librarian notices Collaborators in a library space, he or she, may also scan the area to determine if there are Side-Kicks in the same space or nearby. This helps to identify a library space that suits both personas. If no Side-Kicks are near the Collaborators, then the librarian may ask, how the space could be changed to accommodate both. This process could also be used for flexible spaces where personas from different neighborhoods could come when using the library.

\section{General Principles}

Whether viewed as individually or in neighborhoods, personas represent patterns of use that focuses the questions, "How do patrons use the library?" and "What do patrons need from the library?" The answer to both of these questions is, "It depends." First, it depends on the immediate needs of the patron. Libraries have transformed from stagnant repositories of books, journals, and other resources, to dynamic organizations ready to adjust to the needs of patrons. They offer a wide range of resources and services to meet

This article is (C) Emerald Group Publishing and permission has been granted for this version to appear here (https://sites.lib.byu.edu/scholarsarchive/). Emerald does not grant permission for this article to be further copied/distributed or hosted elsewhere without the express permission from Emerald Group Publishing Limited. 
user needs. Personas help match the user needs with library services offered. They help librarians plan for new or redeveloped services and space.

Second, identifying personas does not equate to stereotyping patrons. While the persona describes common use patterns of a specific user group, the fluid nature of personas used by patrons indicates a kaleidoscope of patron needs and uses. While a single persona describes use patterns, it does not make up the complete set of personas for any single person. The library cannot respond to a single persona and think that they have met the all needs of a patron. A holistic approach needs to be taken that addresses the needs of several personas at key times in the semester.

Finally, personas do not reflect a "one-and-done" approach to understanding patron personas. Instead as more data and insight is acquired, the persona descriptions should be revisited and information added to enrich the description of each persona. Imagine personas as someone that you meet and enjoy being with. As you spend more time with the person you gain more insights into the nature and character of the individual. Over time, your relationship with this person develops. As a close friend, you gain greater insights into how to better interact with the individual in more fulfilling and mutually satisfying ways. So it is with personas. As librarians come to embrace the persona as a long-time friend or colleague, greater insights will come on how to better interact with patrons in this group. A world of possibilities will open between the library and the patron so that the relationship is mutually satisfying and supportive. Librarians are better able to understand and meet patron needs as they better understand the personas found in the library.

\section{Persona-Minded}

An additional step in using personas effectively requires librarians to become personaminded. In this regard one becomes so familiar with personas that each persona is like an old friend. As one moves through the library, responds to an inquiry, meets a need or performs some other library related task, he or she sees personas. In fact, as the librarian moves across campus or in the broader community, the understanding of personas comes with them. For example, if a librarian is out shopping for furniture, he may see a furniture set that would fit in a library space that meets the needs of Chillaxers. Furniture this persona can use for a break from studies or to read a fantasy novel not related to studies. As a librarian visits with engineering faculty, she may see a group study space that would meet the needs of other Collaborators across campus.

Being persona-minded is like taking a group of friends with you wherever you go. Spaces, features, and actions are viewed in terms of meeting persona needs. For example, as you enter a department store with a greeter, the In-and-Outer persona figuratively taps you on the shoulder and asks, "Why does our library not have a greeter who can tell me how to quickly get what I need?" When you check out at a grocery store, the Explorer persona asks, "Why don't we have book displays highlighting collections at the Circulation Checkout and Help Desks so Explorers can browse while waiting to be served?" As you interact with patrons, you begin to see the persona groups that apply to each of them and how you can help enrich their library experience through the use of personas.

Personas become infused into all aspects of library planning, whether new services or changes to the physical building. Being persona-minded enables you to see which personas

This article is (C) Emerald Group Publishing and permission has been granted for this version to appear here (https://sites.lib.byu.edu/scholarsarchive/). Emerald does not grant permission for this article to be further copied/distributed or hosted elsewhere without the express permission from Emerald Group Publishing Limited. 
will use the services or be drawn to the renovated space. If your library is developing a maker-space or a creativity lab, the planner asks which personas will be drawn to this area and in what ways will they use it? Doing this enables planners to see the space being used prior to it being built. As librarians develop their persona-mindedness, a connection with patrons forms that helps meet patron needs. It not only highlights how libraries can change to meet the needs of patrons, but also indicates new directions the library needs to take to meet the needs of patrons.

\section{Applying Personas to Space Design}

Personas provide greater understanding on how library spaces and services are used, may be developed, and can be altered. The following examples illustrate spaces that have a strong connection to personas. While many of these spaces were created prior to the development of personas, they provide insights into spaces the library currently has that meets persona needs, what spaces for specific personas are missing in the library, and how library spaces may be developed to fit the specific personas of patrons. What follows are some specific examples from the Lee Library.

New study carrels. In creating new individual study carrels, designers used a variety of data to inform the design, but understanding the nature of Focusers and Islanders helped to inform features that the carrel needed. For example, both personas want to be selfcontained so that they are not disturbed and have no need to go elsewhere. Adding a regular and a USB plug-in provides easy access to the power needed for electronic devices, as Focusers and Islanders will bring the equipment they need to work alone.

In addition to the power plug-ins, the study carrels also have a white board. The white board also meets the needs of Focusers and Islanders in their studies by providing access to additional resources within a private place. When a right-handed and left-handed study carrel are put together, a two- or three-person pod is formed. Used in this way the individual study carrels meets the needs of small (two or three person) Collaborators. The white board, desk space, and plugins also facilitate this small group of Collaborators.

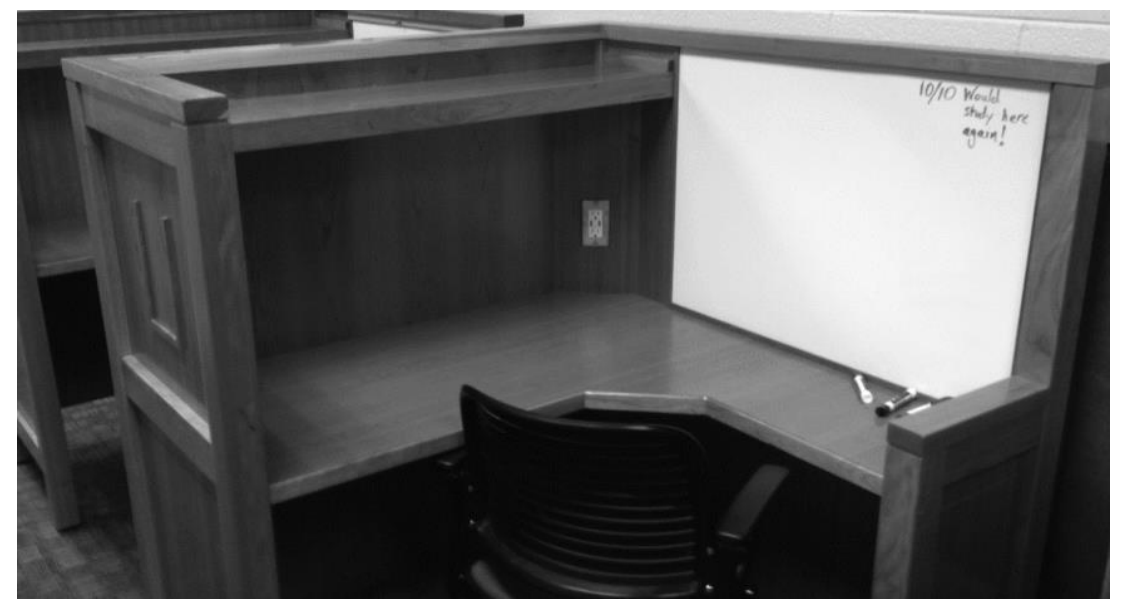

Figure 2. New individual study carrel.

This article is (C) Emerald Group Publishing and permission has been granted for this version to appear here (https://sites.lib.byu.edu/scholarsarchive/). Emerald does not grant permission for this article to be further copied/distributed or hosted elsewhere without the express permission from Emerald Group Publishing Limited. 
Creativity innovation and design lab. One new space in the pilot study stage at the Lee Library is a creativity, innovation and design lab where multi-discipline courses from across campus may be taught. The space provides a unique area within the library where students from different backgrounds come together to complete real-world tasks. The space caters to collaboration with open spaces, adjustable furniture, movable white boards, and group study rooms for break-away tasks. Each of these aspects meets the needs of the Collaborator persona. The open-area and furniture enables groups to adjust and reform depending on the creativity task assigned.

It should be noted that Explorers have also found this space attractive. As they visited the space they became inquisitive about what went on in this space and enquired if they could join. In these cases Explorers joined and became part of the Collaborator group because of the opportunities to explore new ideas. Side Kicks have also used this space to work with one another when courses are not taught.

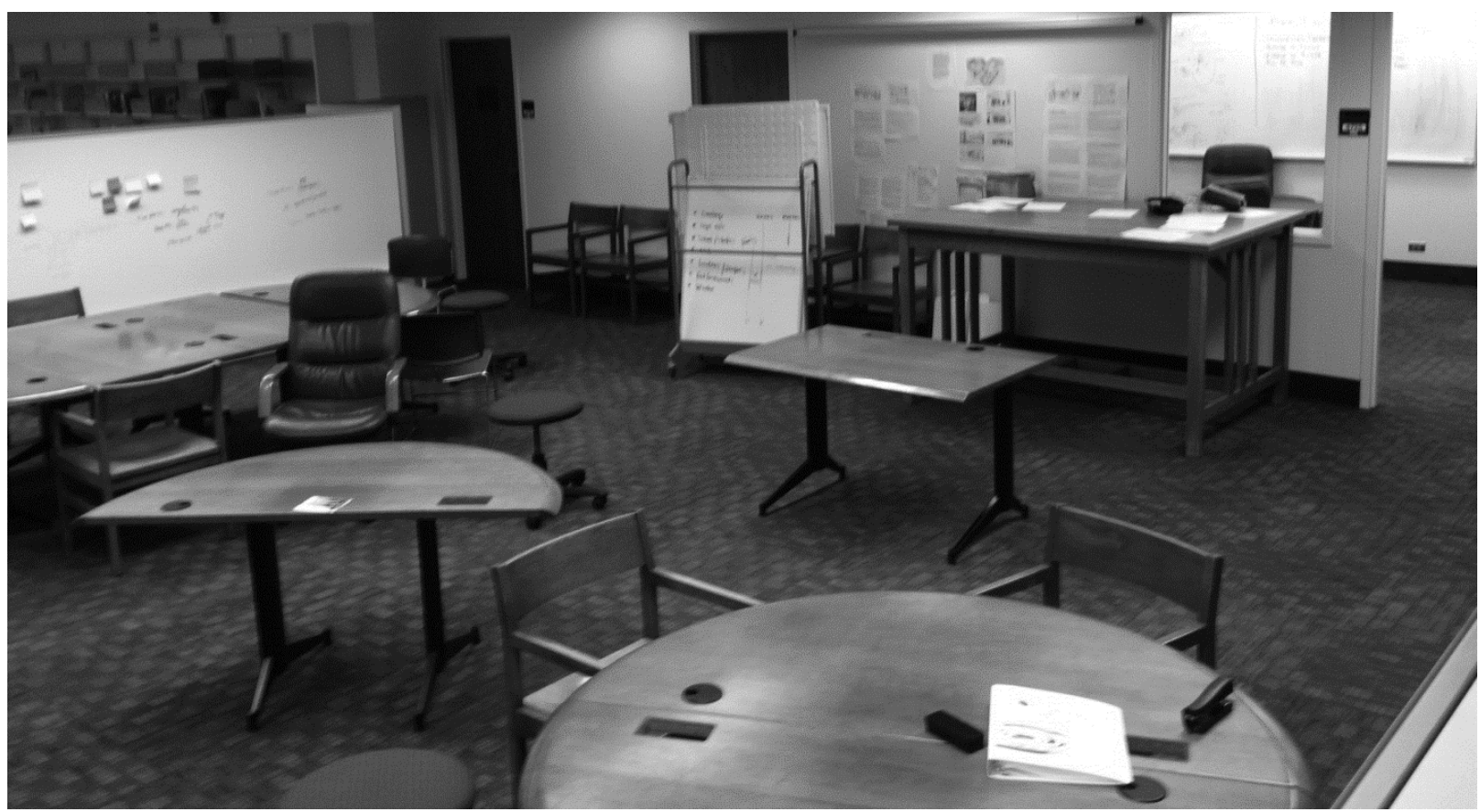

Figure 3. Creativity, innovation and design lab.

Sampler Zone. The area that houses the sampler (non-academic) books was moved from a confined space filled with stacks, tables, and chairs to an open, more airy area more suitable to Chillaxers. Seating is comfortable and centered around a faux-fireplace to create an open relaxed space where Chillaxers can read or relax from studies. The space feels more like being at home or a lounge than a library space.

This article is (C) Emerald Group Publishing and permission has been granted for this version to appear here (https://sites.lib.byu.edu/scholarsarchive/). Emerald does not grant permission for this article to be further copied/distributed or hosted elsewhere without the express permission from Emerald Group Publishing Limited. 


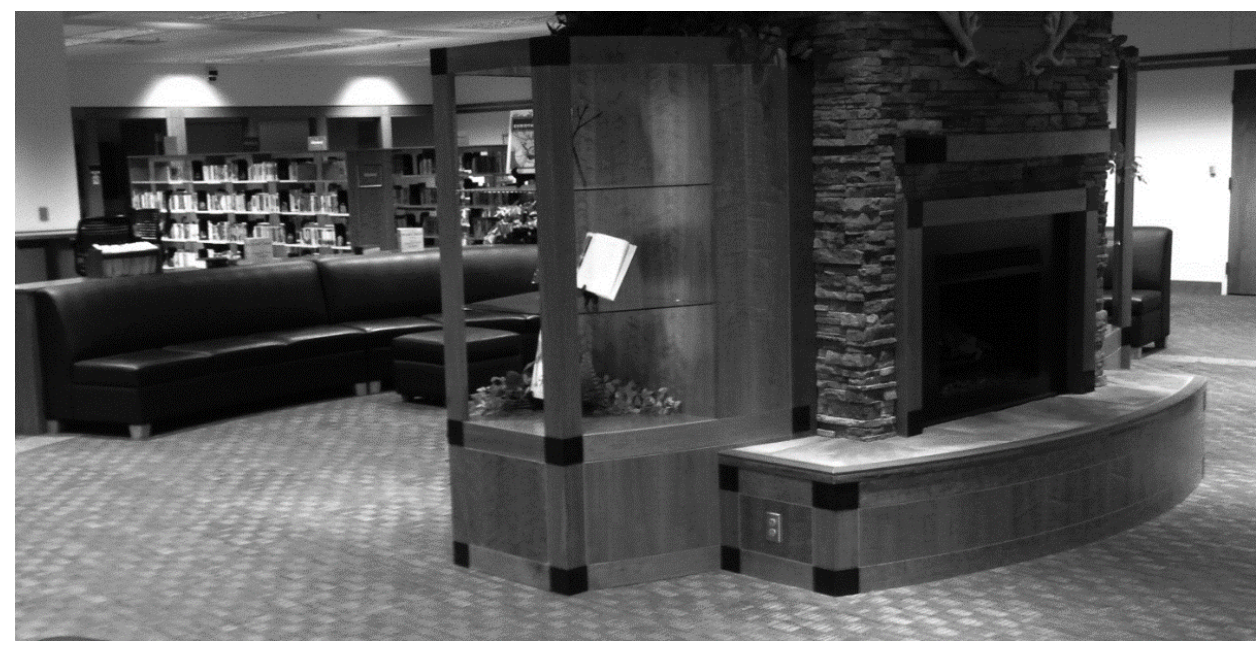

Figure 4. Sampler zone for reading non-academic novels.

Group Study Rooms. On one floor two group study rooms with outside windows were modified to have glass walls and doors. The change provides more light to darker areas creating a space for Collaborators who like natural light. It also provides natural light to other study spaces. The clear glass walls also allow Side-Kicks seated outside the group study rooms to draw support from those using the rooms. They can see groups working inside the room and can draw on the presence and energy of Collaborators in the room to help them with their studies outside of the group study rooms.

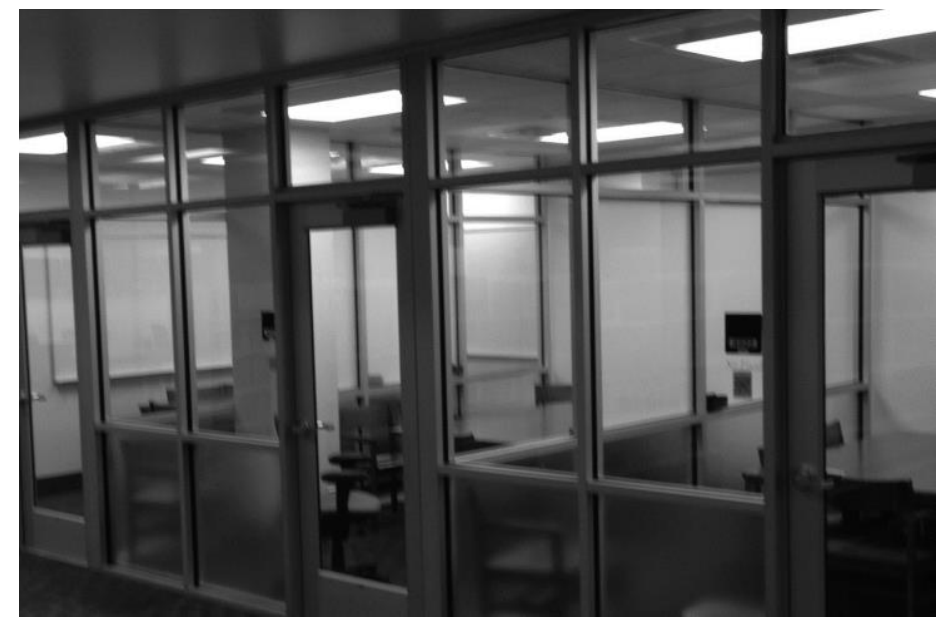

Figure 5. Glass-walled group study rooms.

Alternate study desks. One area, near sunlight and high traffic, used a bar table approach for creating a space for Side-Kicks. In this area students can use the desks while standing or sitting on high chairs. The space provides a quiet study zone where students can see others and be seen. Side-Kicks may also have partner next to them or simply be in an area that encourages them to study seeing others studying. The space is also flexible with comfortable seating that may be used by Chillaxers, Islanders, or others who want a comfortable place to sit and read. This space combines features from two neighborhoods in This article is (c) Emerald Group Publishing and permission has been granted for this version to appear here (https://sites.lib.byu.edu/scholarsarchive/). Emerald does not grant permission for this article to be further copied/distributed or hosted elsewhere without the express permission from Emerald Group Publishing Limited. 
such a way that personas in those neighborhoods feel comfortable with one another and draw energy from one another.

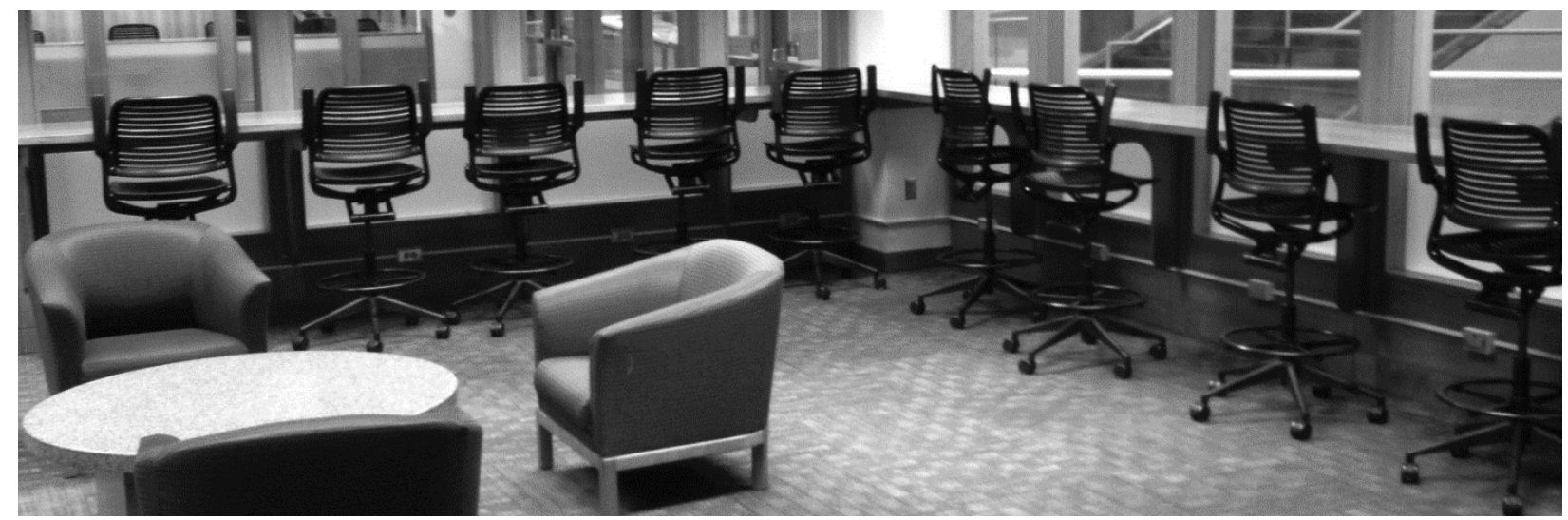

Figure 6. Bar height desks in periodicals study area.

Another alternate desk is located in the media center. The wavy desk design suits an individual user (e.g. Focuser, Islander, or Pirate) who needs to use the computer to complete a project. However, the wavy design also provides privacy and the ability for two or three people to gather around a computer to work on a project together (e.g., Collaborators). The desk design in an open space accommodates the needs of a variety of patron personas who need to use a computer.

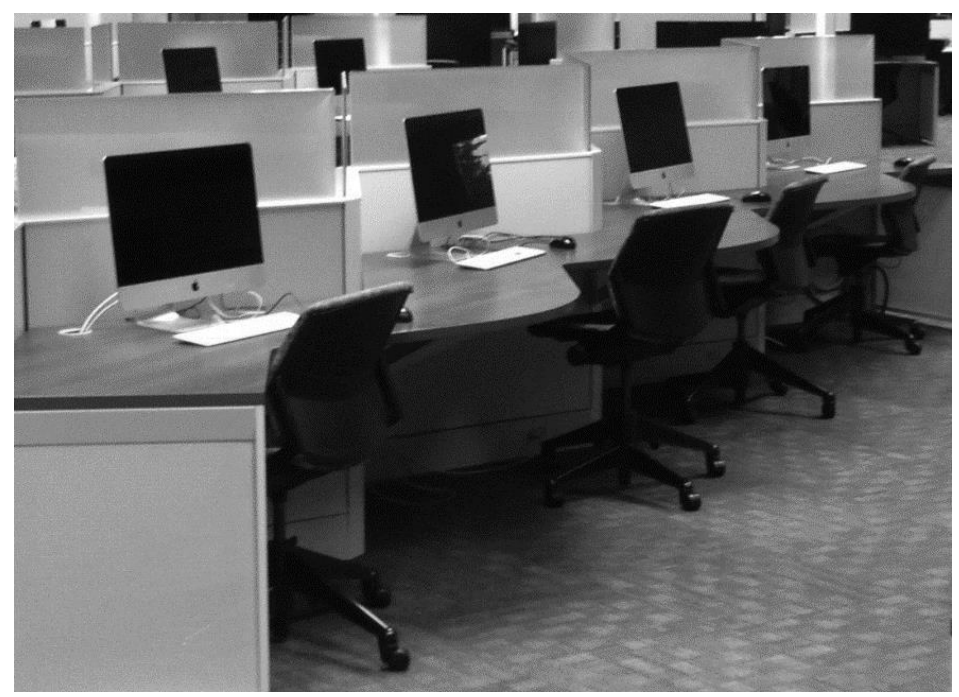

Figure 7. Wave desks found in media center.

Furniture. Another combination provides different furniture in the same space to accommodate different multiple personas from different neighborhoods. The different furniture configurations provide the option for Islanders, Focusers, Side-Kicks and Chillaxers to all use the same space at the same time. While the space is next to a traditional study area, the use of different furniture in the space opens the opportunity for other personas to use the space in a way that meets their needs.

This article is (C) Emerald Group Publishing and permission has been granted for this version to appear here (https://sites.lib.byu.edu/scholarsarchive/). Emerald does not grant permission for this article to be further copied/distributed or hosted elsewhere without the express permission from Emerald Group Publishing Limited. 


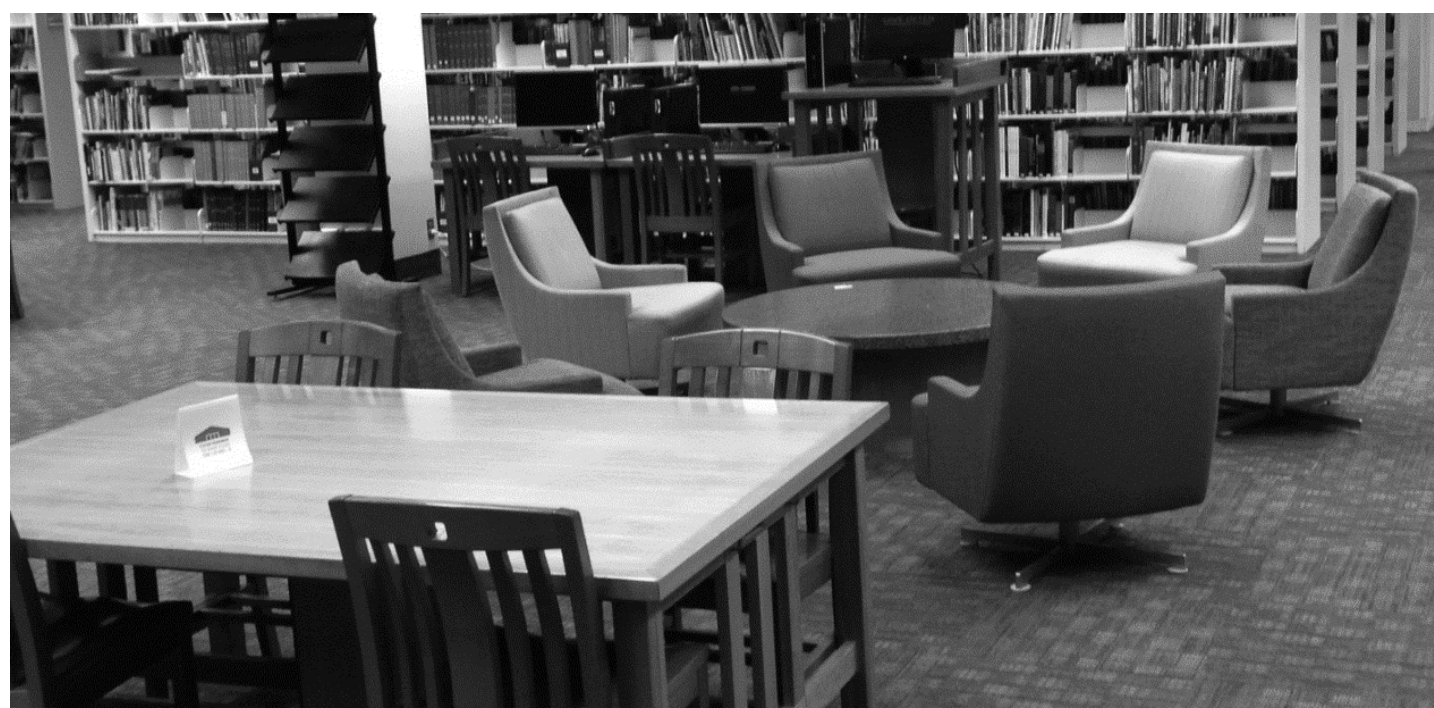

Figure 8. Variety of study furniture to accommodate different persona needs.

While these examples illustrate spaces that meet the needs of different personas within the Lee Library, the power of personas comes not from being able to associate library space with personas, but in using personas to develop library space. As development plans proceed and mock-ups are made, persona-minded planners envision which personas will use the space and what type of amenities will help each persona. Planners are able to create flexible spaces that meet the needs of a single persona or a neighborhood of personas. As planning moves through construction to promotion, patrons are informed as to which spaces are available to meet their needs.

\section{Conclusion}

While initially used in marketing and design, personas or user groups have promising applications for use in libraries. Identifying, developing, and validating personas for a library offers librarians an additional tool to use for planning services and space use. Instead of just conducting post occupancy evaluations that look back to determine if what was designed is being used as planned, personas enable planners to look forward in their planning efforts (Declerq and Cranz, 2014). Personas help to determine if the current library space provides adequate and appropriate room for the type of patrons using the library. It also allows the library to adjust its space as new personas enter the library or increase the amount of needed space.

The examples of personas found at BYU provide specific examples of personas along with how these personas relate to one another via neighborhood descriptions. Some of these personas may be found at other academic libraries, but there is the possibility of eliminating some of these examples or adding new personas. The library space may also define the ways in which the personas relate to one another within their defined neighborhoods. In this way librarians begin to see the library spaces and patrons with different eyes. They become persona-minded.

Becoming persona-minded enables librarians to understand patrons by seeing patrons' use patterns and library spaces through the eyes of patron personas. The persona descriptions and neighborhoods allows the librarian to think and act as if they were that This article is (C) Emerald Group Publishing and permission has been granted for this version to appear here (https://sites.lib.byu.edu/scholarsarchive/). Emerald does not grant permission for this article to be further copied/distributed or hosted elsewhere without the express permission from Emerald Group Publishing Limited. 
persona. As spaces and services are being developed, librarians are able to see the space through personas to predict and to promote library spaces and services. It enables the librarian to determine how the library fits into the life of the patron, rather than how the patron fits into the life of the library.

This article is (c) Emerald Group Publishing and permission has been granted for this version to appear here (https://sites.lib.byu.edu/scholarsarchive/). Emerald does not grant permission for this article to be further copied/distributed or hosted elsewhere without the express permission from Emerald Group Publishing Limited. 


\section{References}

Al-Shboul, M. K. \& Abrizah, A. (2014). Information needs: Developing personas of humanities scholars. The Journal of Academic Librarianship, 40(5), 500-509.

Blomquist, A. \& Arvola, M. (2002). Personas in action: Ethnography of an interaction design team. NordiCHI, 19-23.

Branin, J. J. (2007). Shaping our space. Journal of Library Administration, 46(2), 27-53. doi:10.1300/J111v46n02_04

Brown, R. A. (1992). Students as partners in library design. School Library Journal, 38(2), 31-34.

Cha, S. H., \& Kim, T. W. (2015). What matters for students' use of physical library space? The Journal of Academic Librarianship, 41(3), 274-279.

Cohen, A. (2009). Learning spaces in public libraries. Public Library Quarterly, 28(3), 227233.

Cunningham, H. (2005). Designing a website for one imaginary persona that reflects the needs of the many. Computers in Libraries, 25(9), 15-19.

DeClercq, C. P., \& Cranz, G. (2014). Moving beyond seating-centered learning environments: Opportunities and challenges identified in a POE of a campus library. The Journal of Academic Librarianship, 40(6), 574-584.

Fortini-Campbell, L. (2001). Hitting the sweet spot: How consumer insights can inspire better marketing and advertising. Bruce Bendinger Creative Communications: Chicago.

Goodman, V. D. (2011). Applying ethnographic research methods in library and information settings, International Journal of Libraries \& Information Services, 61(1), 111.

Guenther, K. (2006), "Developing personas to understand user needs", Online, 30(5), 49-51.

Hellstrom, A. \& Eriksson, H. (2013). Among fumblers, talkers, mappers and organisers: Four applications of process orientation, Total Quality Management, 24(6), 733-751.

Idoughi, D., Seffah, A., \& Kolski, C. (2012). Adding user experience into the interactive service design loop: A persona-based approach, Behavior \& Information Technology, 31(3), 287-303.

Khoo, M., Rozaklis L. \& Hall, C. (2012). A survey of the use of ethnographic methods in the study of libraries and library users, Library \& Information Science Research, 34, 82-91.

Leary, M. R. \& Allen, A. B. (2011). Self-Presentational persona: Simultaneous management of multiple impressions, Journal of Personality and Social Psychology, 101(5), 10331049.

Mckay, L. (2010). Adding the persona touch: With an eye on the user experience, some brands are inviting imaginary friends to the party. CRM Magazine 14(2), 19-20.

Mulder, S. \& Yaar, Z. (2007). Approaches to creating personas. In S. Mulder, The user is always right: a practical guide to creating and using personas for the web. Berkeley, CA: New Riders.

Olsen, G. (2004). Making personas more powerful: details to drive strategic and tactical design, Boxes and Arrows. Retrieved from http://boxesandarrows.com/makingpersonas-more-powerful-details-to-drive-strategic-and-tactical-design on 28 April 2015.

This article is (C) Emerald Group Publishing and permission has been granted for this version to appear here (https://sites.lib.byu.edu/scholarsarchive/). Emerald does not grant permission for this article to be further copied/distributed or hosted elsewhere without the express permission from Emerald Group Publishing Limited. 
Pruitt, J. \& Grudin, J. (2003). Personas: Practice and theory. Proceedings of the 2003 conference on designing for user experience, San Francisco, CA.

Schmidt, A. (2014), Creating a common vision, Library Journal, 139(2), 1-2.

Tempelman-Kluit, N. \& Pearce, A. (2014). Invoking the user from data to design. College \& Research Libraries, 75(5), 616-640.

Zaugg, H., \& Rackham, S. (2016). Identification and development of patron personas for an academic library, Performance Measurement and Metrics, 17(2), 124-133.

This article is (C) Emerald Group Publishing and permission has been granted for this version to appear here (https://sites.lib.byu.edu/scholarsarchive/). Emerald does not grant permission for this article to be further copied/distributed or hosted elsewhere without the express permission from Emerald Group Publishing Limited. 